\title{
Conceptual Framework of Service-Based Learning Moderating Effect on The Relationship Between Students' Knowledge of Ethics Course Content and Generic Skill
}

Haslinah Muhamad, Mazlina Mustapha, Soh Wei Ni and Ong Tze San

To Link this Article: http://dx.doi.org/10.6007/IJARBSS/v12-i1/12116

DOI:10.6007/IJARBSS/v12-i1/12116

Received: 11 November 2021, Revised: 14 December 2021, Accepted: 27 December 2021

Published Online: 22 January 2022

In-Text Citation: (Muhamad et al., 2022)

To Cite this Article: Muhamad, H., Mustapha, M., Ni, S. W., \& San, O. T. (2022). Conceptual Framework of Service-Based Learning Moderating Effect on The Relationship Between Students' Knowledge of Ethics Course Content and Generic Skill. International Journal of Academic Research in Business and Social Sciences, 12(1), 1047-1059.

\section{Copyright: (c) 2022 The Author(s)}

Published by Human Resource Management Academic Research Society (www.hrmars.com)

This article is published under the Creative Commons Attribution (CC BY 4.0) license. Anyone may reproduce, distribute, translate and create derivative works of this article (for both commercial and non0-commercial purposes), subject to full attribution to the original publication and authors. The full terms of this license may be seen at: http://creativecommons.org/licences/by/4.0/legalcode

Vol. 12, No. 1, 2022, Pg. 1047 - 1059

Full Terms \& Conditions of access and use can be found at http://hrmars.com/index.php/pages/detail/publication-ethics 


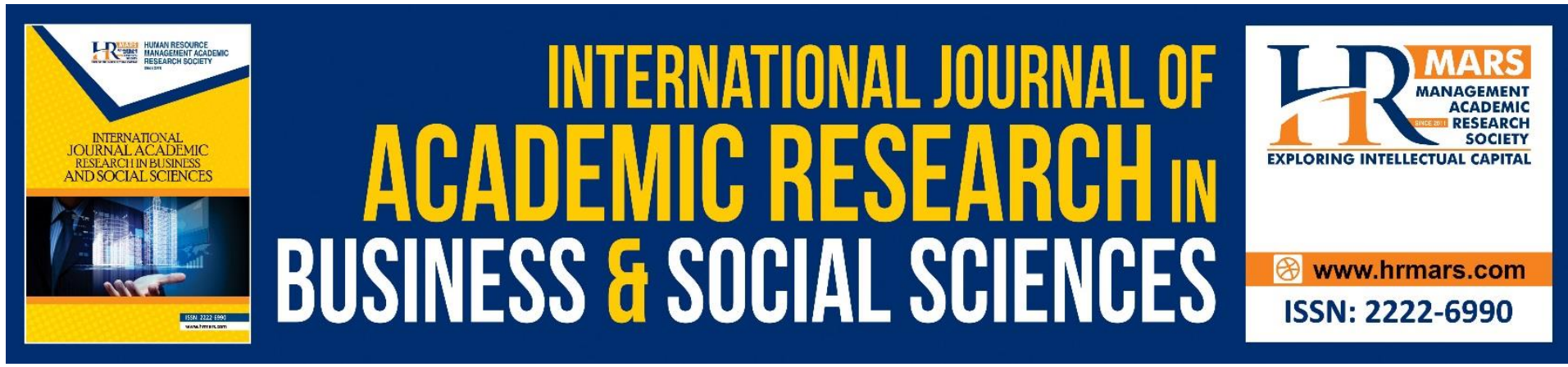

\title{
Conceptual Framework of Service-Based Learning Moderating Effect on The Relationship Between Students' Knowledge of Ethics Course Content and Generic Skill
}

\author{
Haslinah Muhamad, Mazlina Mustapha, Soh Wei Ni and Ong \\ Tze San
}

School of Business and Economics, Universiti Putra Malaysia, Serdang, Selangor, Malaysia

\begin{abstract}
SULAM, a service-based learning approach, was launched on the 13th of April 2019 by the Ministry of Education Malaysia, and the Institute of Higher Learning (IHLs) in Malaysia began to respond to it as part of the new competency requirements. The School of Business and Economics (SBE) at Universiti Putra Malaysia is genuinely active in integrating community service activities in their programs including accounting degrees. Since the Accounting program is said to give very little attention on instilling values, ethics, and integrity, it has been proposed to integrate SULAM into the accounting program to particularly enhance generic skills. Among the subject that is suitable to integrate this approach are Business Ethics and Corporate Governance. Corporate Social Responsibility can be chosen as a proxy of the service-based learning approach. Based on the experiential learning theory, this paper offers the conceptual framework regarding the moderating effect of CSR experiential learning approach (as a proxy of SULAM) in the relationship between the theory of knowledge on ethics and generic skill enhancement for future studies. Knowledge in the course contents will become an independent variable (theory of knowledge) including the concept of CSR and human governance. CSR activity is a moderator and generic skill including emotional intelligence as an extra element will be treated as a dependent variable. The knowledge of course content propose to be measured by a questionnaire or test given to students (pretest, before being involved in the CSR activities), CSR activities can be measured by types such as philanthropy, environment conservation, diversity and labor practices, and volunteerism. The dependent variable which is a generic skill can be measured by performance in post-test for enhancing of knowledge or questionnaire with the same participants or evaluation made by a coordinator in certain industrial players.
\end{abstract}

Keywords: Service-Based Learning, CSR, Experiential Learning, Ethics in Accounting Education

\section{Introduction}

Service-Learning Malaysia or its abbreviation, SULAM was launched on the 13th of April 2019 by the Ministry of Education Malaysia, to be promoted and implemented by Higher Education Institutions. SULAM is the brand name that refers to a service-based learning approach or 
service-learning (SL). This approach is listed by the Higher Education Department of the Ministry of Education Malaysia as one of the high impact educational practices (HIEPs) highlighting the important role of universities in society, and to prepare students to become public intellectuals responsible for resolving society's issues.

The Institute of Higher Learning (IHLS) in Malaysia began to respond to SULAM as the new competency requirements. The School of Business and Economics (SBE) at Universiti Putra Malaysia is genuinely active in integrating sustainability and CSR concepts (which are related to the element of SULAM) for students in all the school's undergraduate programs such as management, economics, and accounting curriculums by utilizing unconventional and experiential methods of teaching. This approach aims to equip students with the skills and confidence to act on their values through careful planning and practice of the university's slogan "with the knowledge we serve".

The institution of higher learning plays a significant role in improving the ethical behavior and responsibility of future graduates, even though it should start from an early age. The effective teaching method at the university level has a great potential to shape the behavior and the professionalism of graduates of all areas including accountancy graduates (Bampton \& Cowton, 2013). This can be seen from the famous quotes below:

\section{"Tell me and I forget. Teach me and I remember. Involve me and I learn". Benjamin Franklin}

Furthermore, from a student's perspective, it is interesting to describe the students' reactions to the use of experiential methods for teaching ethics, corporate social responsibility, and as well as sustainability concepts to business students. This paper discusses the interlinks of SULAM teaching approach proxied by CSR activities, students' performance in ethics education, and other sustainability benefits.

Accounting programs are said to emphasize technical skills and compliance with the rules and regulations (Sikka et al., 2007; Boyce, 2008; Salleh \& Ahmad, 2010; Muhamad et al., 2019) very little attention is given to instill values, ethics, and integrity. Any subject related to ethics and values in the accounting program is seen to be dry, boring, and very subjective in nature. The elements that can enhance empathy, consciousness, and other human elements like CSR (corporate social responsibility), moral judgment, stewardship, and accountability had become supplementary content. Consequently, ethics and corporate governance subjects are lacking the human element (McPhail, 2001; Salleh \& Ahmad, 2010; Muhamad et al., 2019) and this may also contribute to the never-ending story of fraud.

Corporate social responsibility (CSR) is a self-regulating business model that helps a company be socially accountable and be conscious of the kind of impact they are having on all aspects of society, including economic, social, and environmental. To study CSR as part of an accounting program just touches on the surface specifically on awareness and basic knowledge about CSR as well as the framework currently applied by the company. The teaching method used is a case study as suggested by Halatuju 2 and 3 , the program standards document initiated by the Ministry of Education Malaysia for accounting program at Higher Learning Institution especially in public universities. Additionally, CSR can also be taught as a stand-alone subject or embedded in business ethics and corporate governance subjects. 


\section{Literature Review}

The ethics education at the higher education level may influence the ethical behavior of graduates. Consequently, if it is about the behavior of the future accountant, it involves teaching and learning ethics in accounting education. Accounting programs are said to emphasize technical skills and compliance to the rules and regulations (Sikka et al., 2007; Boyce, 2008; Salleh \& Ahmad, 2010; Muhamad et al., 2019) very little attention is given to instill values, ethics, and integrity. The ethics subject is seen to be dry, boring, and very subjective due to the ineffective method of teaching and lacks the human element (Salleh \& Ahmad, 2010; Muhamad et al., 2019). This is probably the cause for the behavioral problem (lack of ethics), which in turn would lead to accounting fraud.

To choose the best method of teaching ethics is a challenge for educators. Institutions of higher learning had introduced ethics in their curriculum either as a standalone subject or embedded in other subjects, being core or elective. In terms of content, ethical dilemma, ethical issues, codes of ethics, and professional conduct, as well as a theory of ethics, had been classified as the core (Muhamad, Salleh, \& Kasim, 2018). Whereas for corporate social responsibility (CSR), moral judgment, stewardship, and accountability had been classified as the supplementary content. However, an emphasis on Corporate Social Responsibility (CSR) has been increased worldwide and has been introduced to be included in business ethics courses and in higher education curriculum (Guillermina, 2016). It is different in the case of the human governance concept. Muhamad, Salleh, \& Kasim, (2018), show that only $2 \%$ of elements of human governance have been embedded in ethics education including one Public Universities (PU) in Malaysia. The following section discusses on the CSR and human governance concept.

\section{Definition of CSR}

Corporate social responsibility (CSR) is a self-regulating business model that helps a company be socially accountable - to itself, its stakeholders, and the public (Yayasan Bursa Malaysia, 2021). By practicing corporate social responsibility, also called corporate citizenship, companies can be conscious of the kind of impact they are having on all aspects of society, including economic, social, and environmental. To engage in CSR means that, in the ordinary course of business, a company is operating in ways that enhance society and the environment, instead of contributing negatively to them (Daudisa \& Vevere, 2020).

CSR issues are becoming increasingly popular, both in the academic and in the business communities in Malaysia. Following the instruction of the International Trade and Industry Ministry Secretary-General Datuk Isham Ishak, all listed companies in Malaysia will have no choice but to comply with the execution of CSR programs stating from 2019 (The Star, 2018). This may come up as a shock to many, but for the firms that understand the benefits of corporate social responsibility, this is merely a challenge. Additionally, the Ministry of Home Affairs (KDN) had approved a publication and social project of CSR Malaysia (can be seen at https://csrmalaysia.org/). CSR Malaysia acts as a bridge to connect both corporate companies and the needy by organizing various events that benefit the poor. The publication shares the unwavering commitment of corporations in Malaysia towards the community at large and their inherent roles as change agents in the socio-economic transformation of Malaysia. Its aspirations for Malaysia go beyond merely generating profits and developing world-class buildings and infrastructures. CSR Malaysia endeavors to promote sustainable economies by 
featuring CSR initiatives of corporations in Malaysia by serving the needy. CSR Malaysia also organizes the annual CSR Malaysia Awards with the support of the Ministry of Women, Family \& Community Development Malaysia where outstanding public listed companies are honored.

Companies that realize that CSR benefits both the company and the community are already doing it. Socially responsible companies are more concerned about the impact of their businesses on society than financial matters. The most common examples of corporate social responsibility are making social and environmentally conscious investments, decreasing carbon footprints and climate change, adjusting corporate policies for environmental benefits, engaging in charity and volunteer activities within the community, and improving labor policies as well as embracing fair trade. In conclusion, there are a million ways through which the firms can contribute to their humanitarian efforts and be on the line of globally sustainable development contribution. In education, only $14.3 \%$ of accounting programs across three regions had embedded CSR knowledge and awareness in their ethics course, and this includes high ranking Public Universities (PU) in Malaysia (Muhamad, Salleh, \& Kasim, 2018)

\section{Choose the Right CSR Activities}

Following the increasing global trend in the connections between business and higher education, educators in Malaysia should be able to respond to the collaboration with the company and produce innovation in teaching methods in any field including business ethics and CSR (Azhar \& Azman, 2021). CSR activities conducted by a company can be categorized into several types which are philanthropy, environment conservation, diversity and labor practices, and volunteerism (Reputation Sciences, 2019)

Philanthropy is defined as philanthropic deeds or other good works, such as volunteering your time or efforts, that benefit others or contribute to society's general well-being (Reputation Sciences, 2019). Philanthropy can be traced back to ancient Greece. Plato, for example, authorized his nephew in his will to use the proceeds of the family property to fund the academy that Plato founded in 347 B.C. The funds aided students and professors in keeping the academy afloat. Philanthropy, for some, is making big financial contributions to maintain or develop university buildings, research institutes, or fund four-year college scholarships. Others define philanthropy as an annual donation to a local theatre or a food pantry.

Whether it's a long-term issue like global climate change or a more local issue like a deadly chemical leak, environmental issues frequently make the news. Companies that join these activities help to mitigate environmental problems by reducing their overall carbon footprint, for example. Although major corporations receive most of the attention for their environmental commitments - General Mills, for example, has pledged to a 28 percent reduction in greenhouse gas emissions - small and mid-sized businesses have lots of chances as well (Reputation Sciences, 2019)

When everyone gets along and work as a team, business executives recognize that diversity in the workplace is going well. Labor policies, on the other hand, must apply to all employees, including those at the top of the organization. The Harvey Weinstein and Steve Wynn scandals demonstrate that no organization is immune to the consequences of sexual harassment 
(Reputation Sciences, 2019). Other workplace diversity challenges have arisen as a result of this movement, which requires attention and constant action. Reviewing the diversity policies and protocol of an organization is important for a business leader to resolve any complaints or violations. This is not only beneficial for the firm's image, but it also aids in the development of a positive workplace culture with high morale and productivity.

Local communities and nonprofits are always in need of assistance. Smart business leaders understand that being productively involved in the community benefits the company as well. Allow the employees to volunteer at a local school to help plant trees or collaborate with the city council to solve homelessness in the neighborhood (Reputation Sciences, 2019). Business executives have the option of deciding where to focus their volunteer activities to benefit both the local community and the company. The most important thing for businesses to do is to pick a cause and donate time to it.

In today's business environment, there are several social responsibility challenges. Based on the goals of management and staff, as well as issues that your customer base is concerned about and the communities in which your business operates, each company must identify the concerns that are relevant to its operations (Daudisa \& Vevere, 2020). The same goes for ethics and governance education. Once the objectives and target for an enhancement to develop specific soft skills have been determined, only the appropriate activities are chosen. Being aware of these priorities is the first step in addressing a skill that needs to develop.

\section{Human Governance}

Human governance promotes the inner-outer approach, which enables a person to be internally governed with good values and belief as well as to choose the best option after considering the effects of their decision-making on others including his/her relationship with God, family, and the society (Muhamad, Salleh, Kasim, \& Suppiah, 2019). There are three principles held which are consciousness, connectedness, and oneness (Salleh \& Ahmad, 2010).

Consciousness is the state or quality of awareness or being aware of an external object or something within oneself. Despite the difficulty in definition, many philosophers believe that there is a broadly shared underlying intuition about what consciousness is. This paper defines consciousness as "awareness or perception of an inward psychological or spiritual fact: intuitively perceived knowledge of something in one's inner self" (Salleh \& Ahmad, 2010).

Interconnectedness and oneness are part of the terminology of a worldview that sees oneness in all things. A similar term, interdependence, is sometimes used instead, although there are slightly different connotations. Both terms tend to refer to the idea that all things are of a single underlying substance and reality, and that there is no true separation deeper than appearances. Some feel that 'interconnectedness' and its similar terms are part of a contemporary lexicon of mysticism, which is based on the same core idea of universal oneness (Salleh \& Ahmad, 2010).

Human governance offers a difference in terms of its objectives in teaching ethics and view on ethics. The objective of ethics education is to increase the quality of students' moral development. Human governance views ethics as having two principal topics: first, the goal 
of human existence, and second, how to achieve (or lose) that goal. Ethics are based on the active struggling of the soul for its distillation (Muhamad, Salleh, Kasim, \& Suppiah, 2019)

When the soul is pure and clean, it will lead to a higher rank, closer to God, our fellow men, and the universe. It is, therefore, necessary to decide which soul (nafs) is fighting, and which is being fought against (bad things) and what things they fight for (good things). A deep disposition is a soul related state that causes the issuance of action from a person without thinking and speculation (Muhamad et al., 2019)

\section{Community Based Learning Approach}

Community-based learning is a teaching and learning strategy that integrates meaningful community engagement with instruction and reflection to enrich the learning experience with a greater emphasis on reciprocal learning and reflection (Farnsworth, Frantz, \& McCune, 2012). Community-Based Learning (CBL) is a pedagogical approach that is based on the premise that the most profound learning often comes from experience that is supported by guidance, context-providing, foundational knowledge, and intellectual analysis (Magzoub \& Schmidt, 2000). The opportunity for students to bring thoughtful knowledge and ideas based on personal observation and social interaction to a course's themes and scholarly arguments brings depth to the learning experience for individuals and to the content of the course.

The communities of which we are a part of can benefit from the resources of our faculty and students, while the courses can be educationally transformative in powerful ways. It also refers to a wide variety of instructional methods and programs that educators use to connect to what is being taught in schools to their surrounding communities, including local institutions, history, literature, cultural heritage, and natural environments. Communitybased learning is also motivated by the belief that all communities have intrinsic educational assets and resources that educators can use to enhance the learning experience for students. CBL is a field-based "experiential learning" with community partners as an instructional strategy-and often a required part of the course (Farnsworth, Frantz, \& McCune, 2012). The idea is to give students direct experience with issues they are studying in the curriculum and with ongoing efforts to analyze and solve problems in the community. A key element in these programs is the opportunity that students must both apply what they are learning in realworld settings and reflect in a classroom setting on their service experiences. These programs model the idea that giving something back to the community is an important college outcome and that working with community partners is good preparation for citizenship, work, and life.

\section{Experiential Learning Theory}

One of the most prominent methods of learning is David Kolb's work on the experiential learning cycle. The experiential learning cycle is a four-step learning process that occurs numerous times throughout each contact and experience: Observe - Reflect - Consider - Act. (Institute of Experiential Learning, 2021)

It's a learning process initiated by a concrete experience, which demands reflection, review, and perspective-taking about the experience; with abstract thinking to reach conclusions and conceptualize the meaning of the experience; leading to a decision to act, engaging in active experimentation, or trying out what you've learned (Institute of Experiential Learning, 2021) 
This cycle is so natural and organic that people engage in it without being aware that they are learning. It happens almost effortlessly all the time and is constantly transforming our lives. Most people have preferences for the way they use this learning cycle, focusing on some modes more than others. The opinion on experiential learning theory is summarized in the diagram below.

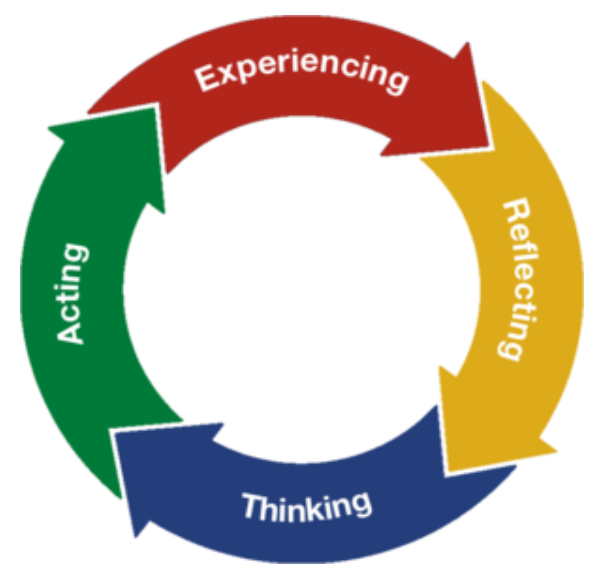

Figure 1: Experiential Learning Theory

Sources: Institute of Experiential Learning, (2021)

\section{Propose Framework}

To respond to service-based learning approach or service-learning (SULAM) listed by the Higher Education Department of the Ministry of Education Malaysia, this paper tries to propose a conceptual framework on the moderating effect of SULAM which is proxied by CSR activities in the relationship between knowledge in the course content of ethics as well as corporate governance and at generic skills enhancement. The summary is shown in the below figure.

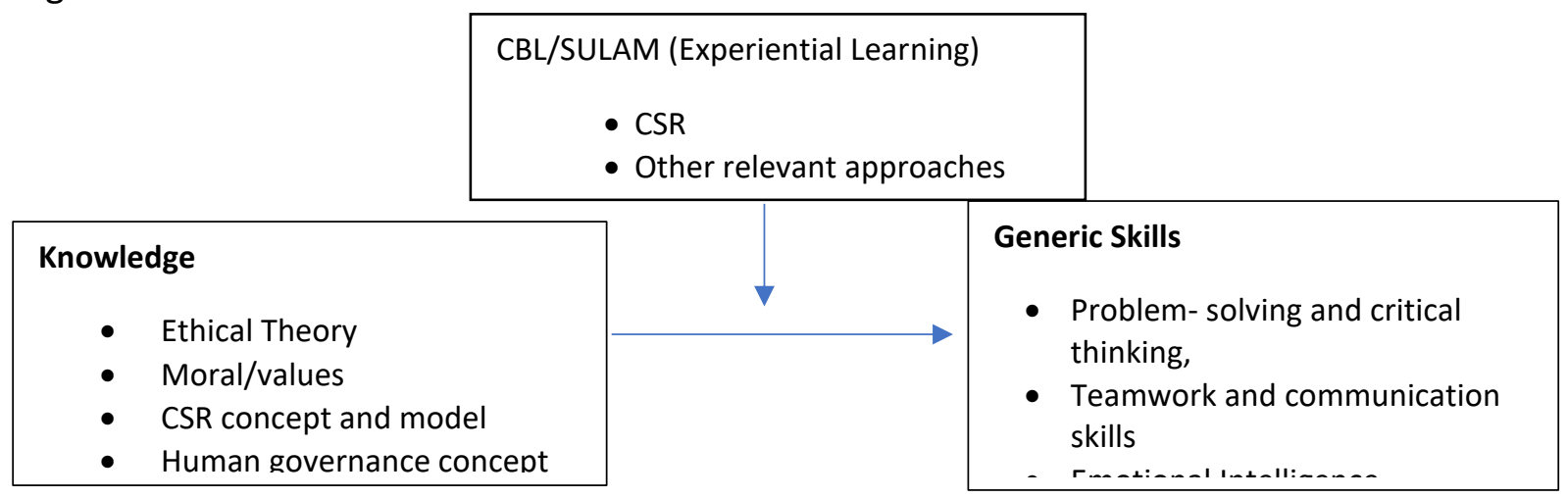

Figure 2: Proposed Research Framework

\section{CSR as Moderator Variable}

Working with a community partner has the benefit of bringing students into meaningful contact with future employers, customers, clients, and colleagues. Students experience higher levels of engagement and take a deeper approach to learning when they can apply what they are studying to address a real-world problem. They can apply theory to the specific project and have a deeper understanding of the subject matter. They can improve critical thinking, problem-solving, presentation, analytical, teamwork, and interpersonal skills. They 
can experience what it is like to work on real problems relevant to their discipline and reflect on that learning in a safe and supporting environment.

Among the benefit of using CSR or other community service are the opportunities to learn in a unique community and environment. CSR or other community service are seen as an important approach to train accountants who are willing and able to work in underserved areas (particularly rural areas) and in difficult as well as challenging conditions (Farnsworth et al., 2012). Magzoub \& Schmidt (2000) argue that CSR or other community service present students with unique opportunities to learn in an environment that typically resembles what students will come across in their later professional life, which, in turn, will improve their performance.

CSR or other community service also can equip students with possible competencies and skills which they might not have learned otherwise e.g., leadership skills, the ability to work in a team, and communication skills. Through CBE, students have the distinctive opportunity to apply these skills, which are essential for their professional life later (Magzoub \& Schmidt, 2000). The community is also a source of independent assessors for both students and the program (Magzoub \& Schmidt, 2000; Tormo-Carbó, Oltra, Seguí-Mas, \& Klimkiewicz, 2016)

CSR or other community service, in addition, renders opportunities for partnership between the community, university, and public sector as well as private sector. This gives the university political and moral support to realize its objectives and play an essential role in decisionmaking concerning the promotion of the education system and services in the community (Magzoub \& Schmidt, 2000; Ruiz-Palomino, Martínez-Cañas, \& Jiménez-Estévez, 2019; Daudisa \& Vevere, 2020)

\section{Graduates' Generic Skill as Dependent Variable}

Education in Malaysia is an ongoing effort towards further developing the potential of individuals in a holistic and integrated manner, as well as to produce individuals who are intellectually, spiritually, emotionally, and physically balanced and harmonious, based on a firm belief in and devotion to God. Such effort is designed to produce Malaysian citizens who are knowledgeable and competent, who possess high moral standards, and who are responsible and capable of achieving a high level of personal well-being as well as being able to contribute to the harmony and betterment of the family, the society and the nation at large (Ministry of Education Malaysia, 2018)

To be parallel and able to achieve the above mission, institutions of higher learning must produce students with a skill that can enhance the university graduates' employability or entrepreneurship and lifelong learning abilities. Such skill will help them cope with an unknown future, as well as enable them to act for the social good. This skill is known as generic skill. Generic skills (GS) are defined as transferable, non-discipline-specific skills that may be achieved through learning and can be applied in the study, work, and life contexts (Pham \& Jackson, 2020). These skills include but are not limited to, communication, teamwork, problem-solving, and critical thinking skills, creativity, resilience (Hager \& Holland, 2006) as well as among several others such as emotional intelligence. 
Emotional intelligence (EI) refers to the ability to perceive, control, and evaluate emotions. Some researchers suggest that emotional intelligence can be learned and strengthened, while others claim it's an inborn characteristic (Cherry, 2020). Researchers suggest that there are four different levels of emotional intelligence including emotional perception, the ability to reason using emotions, the ability to understand emotions, and the ability to manage emotions. Other than that, Daniel Goleman's model suggests four domains of El which are self-awareness, self-management, social awareness, and relationship management (Ocelot Team, 2016). This famous model has been explained in his book titled "Emotional intelligence: why it can matter more than IQ" published in 1995.

Understanding and accurately perceiving emotions begins with the ability to recognize emotions. Understanding nonverbal signs such as body language and facial expressions may be required in many instances. The second phase is to use emotions to stimulate thinking and cognitive activity, which is known as reasoning with emotion. Emotions assist us in prioritizing what we pay attention to and how we react to it. Following the third step of comprehending emotions, the feelings we experience might have a wide range of meanings. When a person expresses furious emotions, the observer must determine what is causing the individual's anger and what it could indicate. The fourth step entails dealing with emotions. The ability to successfully manage emotions is a critical component of emotional intelligence at the greatest level. Emotional management includes regulating emotions and behaving correctly, as well as responding to the emotions of others (Cherry, 2020).

In recent years, there has been a surge in interest in teaching and learning social and emotional intelligence. Many schools now incorporate social and emotional learning (SEL) programs as part of their curriculum (Cherry, 2020). People who have strong emotional intelligence can consider the perspectives, experiences, and emotions of other people and utilize that information to explain why they behave the way they do.

To prepare future accountants for a career in accounting, the faculty must adapt to environmental changes and the demands of their major stakeholders by altering the curricula to cover both discipline-specific technical abilities and a larger range of generic skills. All stakeholders anticipate strong accounting and analytical skills, as well as a set of soft interpersonal professional skills, to improve their employability and effectiveness in the business and life in general.

In Malaysia, key skills such as English language competence and soft skills such as creativity, communication, and critical thinking are not addressed to the required levels (MOHE, 2016). The skills gap among graduates is a phenomenon that affects regions, countries, and businesses of all kinds. What is the significance of the English language? Due to the diversity of races in Malaysia and the need to be competitive in a global setting, English is a current popular medium of communication.

\section{Proposed Method}

This proposed study will require final year students in the accounting program at Higher Learning Institutions to be engaged in CSR activities conducted by a high reputation company organization. Students need to communicate and get permission to join the company's CSR activities through any relevant medium (such as email, formal letter). Consequently, after 
they complete the task, students need to do the report verbally (through presentation) and write up a report to submit to the instructor. The questionnaire will be used to measure the student's knowledge of the course content such as ethical theory, CSR concept, moral values as well as human governance concept before and after the involvement in the activities. The moderating variable which is CSR-based learning can be measured by the type of CSR activities that students get involved or participate in. The generic skills such as problem-solving, teamwork, and emotional intelligence as well as communication will be measured or evaluated by the evaluator (person in charge) in the activities conducted by the company or organization. Communication and other relevant skills can also be measured based on preengagement, presentation report (verbally) and writing up report (writing skill) using the rubrics prepared by the School of Business and Economics under the accreditation unit. The evaluation will be given to the participants of the CSR activities as well as the coordinator of the program in the organization that is involved in the activities.

\section{Conclusion}

This paper proposes the engagement in community-based participatory education research, integrating CSR activities (Community Engagement) in Academic Coursework such as Business Ethics and Corporate Governance courses. Although there are many advantages listed in literature such as deep understanding about the theory related to the subject matter (as an example ethical theory, moral, values), this paper-like suggest two other concepts which are CSR concept and model as well as the human governance concept. This paper also suggests enhancing generic skills, an example being emotional intelligence, which are lacking in research as dependent variables.

\section{Acknowledgement}

This work was funded and supported by the School of Business and Economics Research Grant of Universiti Putra Malaysia [reference number UPM/SPE/800-3/3/1/GPSPE/2020/6303801]

\section{References}

Azhar, A., \& Azman, A. (2021). Corporate Social Responsibility in Educational Programme among Malaysian Primary Schools: Perspectives from Corporate Companies in Malaysia. Studies of Applied Economics, 1-12.

Bampton, R., \& Cowton, C. (2013). Taking stock of accounting ethics scholarship: A review of the journal literature. Journal of Business Ethics, 549-563.

Boyce, G. (2008). The social relevance of ethics education in global(ising) era: From invidual dilemmas to systemic crises. Critical Perspectives on Accounting 19, 255-290.

Cherry, K. (2020). Verywell mind. Retrieved from What Is Emotional Intelligence?: https://www.verywellmind.com/what-is-emotional-intelligence-2795423

Daudisa, T., \& Vevere, V. (2020). Importance of professional ethics and corporate social responsibility within business studies curriculum within context global economy. SHS Web of Conferences 74, 04004 (pp. 1-9). EDP Sciences.

Farnsworth, T. J., Frantz, A., \& McCune, R. (2012). Community-based distributive medical education: Advantaging society. Medical Education Online, 1-10.

Farrag, D. A., \& Obeidat, S. (2020). Integrating Sustainability and CSR Concepts in the College of Business \& Economics (CBE) Curriculum: An experiential learning approach. Retrieved from Research gate: 
https://www.researchgate.net/publication/341714148_Ethics_CSR_and_Sustainahtt ps://www.researchgate.net/publication/341714148_Ethics_CSR_and_Sustainability_ ECSRS_Education_in_the_Middle_East_and_North_Africa_MENA_Region_Conceptu alization_Contextualization

Goleman, D. (1995). Emotional intelligence: why it can matter more than IQ. Bantam Books. Hager, P., \& Holland, S. (2006). Graduate Attributes, Learning and Employability. Netherlands: Springer.

Institute of Experiential Learning. (2021). Institute of Experiential Learning. Retrieved from What Is Experiential Learning?:

https://experientiallearninginstitute.org/resources/what-is-experiential-learning/\#

Magzoub, M., \& Schmidt, H. (2000). Some Principles Involved in Community-Based Education. In H. Schmidt, M. Magzoub, G. Feletti, Z. Nooman, \& P. V. (Eds.), Handbook of Community-Based Education: Theory and Practices. Maastricht: Network Publications.

McPhail, K. (2001). The Other Objective of Ethics Education: Re-humanising the Accounting Profession- A Study of Ethics Education in Law, Engineering, Medicine and Accountancy. Journal of Business Ethics, 279-298.

Ministry of Education Malaysia. (2018). Quick Facts 2018 Malaysia Educational Statistics. Putrajaya: Educational Data Sector, Educational Planning and Research Division, Ministry of Educational Malaysia.

MOHE. (2016). Hala Tuju 3 -Reassessment Report on Accounting Programme at Public Universities of Malaysia 2016. Shah Alam: Pusat Penerbitan Universiti (UPENA).

Muhamad, H., Salleh, A., \& Kasim, N. A. (2018). Manner Ethics Addressed in Existing Accounting Curriculum. International Journal of Academic Research in Business and Social Sciences, 987-1012.

Muhamad, H., Salleh, A., Kasim, N. A., \& Suppiah, S. D. (2019). Human Governance: How Ethical Behaviour of Accountants can be Improved? International Journal of Academic Research in Business and Social Sciences, , 370-385.

Ocelot Team. (2016). Ocelot. Retrieved from 4 Components of Emotional Intelligence (EQ): https://www.ocelotbot.com/blog/4-components-emotional-intelligence-eq

Pham, T., \& Jackson, D. (2020). The need to develop graduate employability for a globalized world. In T. L. Nghia, T. Pham, M. Tomlinson, K. Medica, \& C. D. Thompson, Developing and Utilizing Employability Capitals : Graduates' Strategies across Labour Markets (p. 21). New York: Routledge.

Reputation Sciences. (2019). Corporate Social Responsibility (CSR) and Why It Matters. Retrieved from Reputation Sciences:

https://www.reputationsciences.com/corporate-social-responsibility/

Ruiz-Palomino, P., Martínez-Cañas, R., \& Jiménez-Estévez, P. (2019). Are Corporate Social Responsibility Courses Effective? A Longitudinal and Gender-Based Analysis in Undergraduate Students. Sustainability, 1-17.

Salleh, A., \& Ahmad, A. (2010). Human Governance: Bringing the Meaning of Integrity in life of Professional Accountants. Malaysia: Malaysia Institute of Accountant (MIA).

Sikka, P., Haslam, C., Kyriacou, O., \& Agrizzi, D. (2007). Professionalizing claims and the state of UK professional accounting education: some evidence. Accounting Education: an International Journal, 3-21.

The Star. (2018). Be innovative with CSR efforts. Retrieved from The Star: https://www.thestar.com.my/opinion/letters/2018/10/29/be-innovative-with-csrefforts 
Thirumuru, P., Thirukkovela, T., \& Kumar, V. (2015). Corporate Social Responsibility in Education: A Case Study of Hetero Group. 4th Int'l Conference on Research in Humanities, Sociology \& Corporate Social Responsibility (RHSCSR'15) (pp. 1-4). Penang (Malaysia: ICEHMED915011.

Tormo-Carbó, G., Oltra, V., Seguí-Mas, E., \& Klimkiewicz, K. (2016). How effective are business ethics/CSR courses in higher education? 2nd International Conference on Higher Education Advances, HEAd'16, (pp. 567 - 574). València, Spain: Procedia - Social and Behavioral Sciences 228.

Malaysia, Y. B. (2021). CSR Pillars. Retrieved from Bursa Malaysia:

https://www.bursamalaysia.com/about_bursa/sustainability/yayasan-bursamalaysia/beneficiary-application 